\title{
Erratum to: Ultrasound evaluation of the anatomy of the vessels in relation to the femoral nerve at the femoral crease
}

\author{
W. Ty Muhly $\cdot$ Steven L. Orebaugh
}

Published online: 17 August 2011

(C) Springer-Verlag 2011

Erratum to: Surg Radiol Anat (2011) 33:491-494

DOI 10.1007/s00276-010-0755-9

In the original publication of this article the first and last name of the author W. Ty Muhly was incorrectly displayed. This is now corrected here as first name "W. T." and family name "Muhly".

The online version of the original article can be found under doi:10.1007/s00276-010-0755-9.

W. T. Muhly

Department of Anesthesiology,

Children's Hospital of Philadelphia,

Philadelphia, USA

S. L. Orebaugh ( $\square)$

Department of Anesthesiology,

University of Pittsburgh School of Medicine,

UPMC-Southside Hospital, 2000 Mary Street,

Pittsburgh, PA 15203, USA

e-mail: orebaughs1@anes.upmc.edu 